\title{
Antineoplastic Agent Combination SM-88
}

National Cancer Institute

\section{Source}

National Cancer Institute. Antineoplastic Agent Combination SM-88. NCI Thesaurus.

Code C124051.

An orally bioavailable, proprietary combination of four agents with potential

antineoplastic activity. Although the four agents and their exact mechanisms of action are not publicly known, the components of SM-88 appear, upon oral administration, to work synerg istically to increase the amount of free radicals in cancer cells, thereby inducing oxidative stress and selective killing of the cancer cells. 